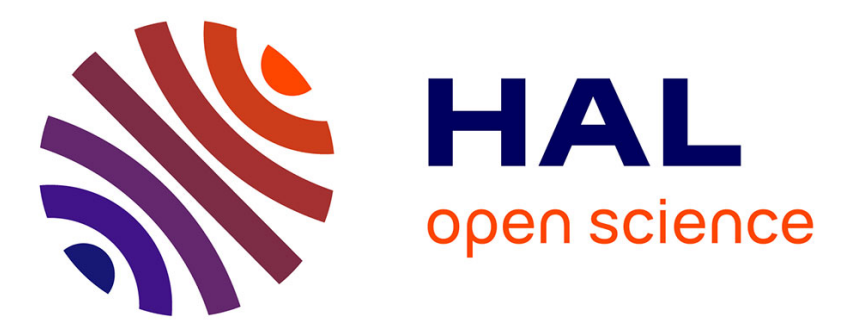

\title{
Sensorimotor Perturbation Induces Late and Transient Molecular Synaptic Proteins Activation and Expression Changes
}

Julie Fourneau, Marie-Hélène Canu, Erwan Dupont

\section{- To cite this version:}

Julie Fourneau, Marie-Hélène Canu, Erwan Dupont. Sensorimotor Perturbation Induces Late and Transient Molecular Synaptic Proteins Activation and Expression Changes. Journal of Molecular Neuroscience, 2021, Journal of Molecular Neuroscience, 10.1007/s12031-021-01839-1 . hal-03227739

\section{HAL Id: hal-03227739 \\ https://hal.univ-lille.fr/hal-03227739}

Submitted on 17 May 2021

HAL is a multi-disciplinary open access archive for the deposit and dissemination of scientific research documents, whether they are published or not. The documents may come from teaching and research institutions in France or abroad, or from public or private research centers.
L'archive ouverte pluridisciplinaire HAL, est destinée au dépôt et à la diffusion de documents scientifiques de niveau recherche, publiés ou non, émanant des établissements d'enseignement et de recherche français ou étrangers, des laboratoires publics ou privés. 


\title{
Sensorimotor perturbation induces late and transient molecular synaptic proteins activation and expression changes
}

\author{
Julie Fourneau ${ }^{1}$, Marie-Hélène Canu ${ }^{1}$, and Erwan Dupont ${ }^{1}$ \\ (1) Univ. Lille, Univ Artois, Univ Littoral Côte d'Opale, ULR7369, URePSSS - Unité de Recherche \\ Pluridisciplinaire Sport Santé Société, F-59000 Lille, France.
}

Correspondence: Marie-Hélène Canu, EURASPORT, 413 Avenue Eugène Avinée, 59120, Loos, France.

E-mail: marie-helene.canu@univ-lille.fr

ORCID ID

JF 0000-0001-6566-5941

MHC 0000-0003-4035-9619

ED 0000-0003-0777-9734

\begin{abstract}
Plasticity of the cerebral cortex following a modification of the sensorimotor experience takes place in several steps that can last from few hours to several months. Among mechanisms involved in the dynamic modulation of the cerebral cortex in adults, it is commonly proposed that short-term plasticity reflects changes in synaptic connections. Here, we were interested in the time-course of synaptic plasticity taking place in the somatosensory primary cortex all along a 14-day period of sensorimotor perturbation (SMP), as well as during a recovery phase up to 24 hours. Activation and expression level of pre- (synapsin 1, synaptophysin, synaptotagmin 1) and postsynaptic (AMPA and NMDA receptors) proteins; postsynaptic density scaffold proteins (PSD-95 and Shank2); cytoskeletal proteins (neurofilaments-L and $\mathrm{M}, \beta 3$-tubulin, synaptopodin, $\mathrm{N}$-cadherin) was determined in cortical tissue enriched in synaptic proteins. During the SMP period, most changes were observed as soon as D7 in the presynaptic compartment and were followed, at D14, by changes in the postsynaptic compartment. These changes persisted at least until $24 \mathrm{~h}$ of recovery. Proteins involved in synapse structure (scaffolding, adhesion, cytoskeletal) were mildly affected and almost exclusively at D14. We concluded that experience-dependent reorganization of somatotopic cortical maps is accompanied by changes in synaptic transmission with a very close time-course.
\end{abstract}

Keywords: sensorimotor perturbation - somatosensory cortex - synaptic plasticity - synaptic proteins 


\section{Declarations:}

Funding: This work was supported by the program VisionnAIRR - "Glycoplasticité" (Hauts-de-France regional council, France).

Conflict of interests: The authors declare no competing financial interests.

Ethics approval: All procedures described below were carried out in accordance with European Communities Council Directive 2010/63/UE, and were approved by Regional Committee on Ethics of Animal Experiments of Nord Pas-de-Calais region (CEEA 75, reference Number: APAFIS\#4733-20 16032917266176v4).

Consent for publication: All authors have approved the last version of the manuscript.

Availability of data and material: The datasets generated during the current study are available from the corresponding author on reasonable request.

Code availability: N/A.

Author contributions: JF, ED, MHC; Methodology: JF, ED; Formal analysis and investigation: JF, ED; Writing: JF, ED, MHC; Funding acquisition: ED; Supervision: ED, MHC. 


\section{Introduction}

Sensory experience shapes neural circuits throughout life via experience-dependent plasticity. Changes in neural circuits, in turn, allow the brain to adapt to recent sensory, motor, and perceptual experiences of animals in their ever-changing environments (Kole et al. 2018).

The mammalian primary somatosensory cortex processes sensory information originating from the whole body. This cortical region is organized somatotopically: the different areas of the body are represented not in proportion to the actual size of the body parts, but rather to their functional importance (Feldman and Brecht 2005). Taking advantage of this organizational principle, previous studies have shown that periods of sensorimotor perturbation (SMP), and in particular of hindlimb unloading, induce a reduction in the cortical representation of the hindlimbs (Dupont et al. 2001; Mysoet et al. 2014; Mysoet et al. 2015), and changes in cortical excitability (Canu et al. 2010; Dupont et al. 2003).

Very little is currently known about time-course of cortical reorganization in adult rats submitted to a period of SMP and their subjacent mechanisms. Our previous studies have demonstrated that, even though 1 day of SMP was not sufficient to detect global and significant changes in somatosensory cortex, a disorganization of the cortical representation of the hindpaw was observed on the $7^{\text {th }}$ day and then, a decrease in this somatotopic area was well-established on the $14^{\text {th }}$ day. Very remarkably, this decrease was transient and reversible, since $6 \mathrm{~h}$ of recovery - consisting in a return to full weight bearing - was sufficient to restore the size of the cortical representation of the hindpaw (Dupont et al. 2001; Langlet et al. 1999). The "recovery phase" is thus incredibly short compared to the "induction phase", i.e. to the time necessary for cortical changes to appear.

Several mechanisms may be involved in the dynamic modulation of the somatosensory cortical maps in adults. It is commonly proposed that short-term plasticity reflects changes in synaptic connections and morphological changes in dendritic spines. At the level of the thalamocortical network, the experience-dependent plasticity of the primary somatosensory cortex would depend on synaptic masking/unmasking processes (Buonomano and Merzenich 1998; Coq and Xerri 1998; Wallace and Fox 1999). A period of SMP would thus cause a reduction in the flow of sensory information, which could lead to the masking of synapses in the hindpaw cortical area affected by SMP, and consequently, induce a reduction in this cortical surface of representation. Conversely, the increase in the flow of sensory information could induce the unmasking of latent synapses through changes in excitation/inhibition balance (Feldman et al. 1999; Pearson et al. 1987; Xerri 2008).

Strengthening and maintaining of synaptic transmission is defined by long-term potentiation (LTP) (Bliss and Lomo 1973), while weakening of synaptic force is defined by long-term depression (LTD) (Dudek and Bear 1992). These processes make it possible to transmit information in a more or less "effective" or "strong" manner according to previous experience. This overall property, known as synaptic efficacy, is the basis of information storage in the brain. The LTP and LTD processes are dependent on glutamate receptors, the NMDA (N-methyl-D-aspartic acid) and AMPA receptors ( $\alpha$ amino-3-hydroxy-5-methyl-4-isoxazolepropionic acid).

A previous study has highlighted many synaptic changes after a 14-day period of SMP (Fourneau et al. 2018). We observed changes in activation and expression of presynaptic proteins involved in the trafficking and release of synaptic vesicles (synapsin 1, synaptophysin) and postsynaptic proteins (PSD-95 or the GluA2 subunit of AMPAR). The results are in favor of an impairment of synaptic efficacy in somatosensory cortex of SMP rat. However, no study to date has been interested in the 
evolution of synaptic and cytoskeletal proteins during the different phases of somatosensory cortex reorganization.

Thus, the main objective of this study was to observe the evolution of activation and expression of a set of synaptic proteins during the time-course of cortical reorganization and recovery induced by a period of SMP. In order to have a global overview of synaptic plastic mechanisms, we studied proteins that have different functions within the synapse namely pre- (synapsin 1 , synaptophysin, synaptotagmin 1) and postsynaptic (AMPA and NMDA receptors) proteins; postsynaptic density scaffold proteins (PSD-95 and Shank2); cytoskeletal proteins (neurofilaments-L and M, $\beta 3$-tubulin, synaptopodin, N-cadherin).

\section{Materials and Methods}

\section{Animals}

The study was not pre-registered and not blinded. All procedures described below were carried out in accordance with European Communities Council Directive 2010/63/UE, and were approved by Regional Committee on Ethics of Animal Experiments of Nord Pas-de-Calais region (CEEA 75, reference Number: APAFIS\#4733-2016032917266176v4). All efforts were made to minimize number of animals and their suffering by conducting a power analysis calculation to predetermine the sample size required to conduct this study.

Male Wistar rats (Charles River, France), 10-12 weeks of age (280-320g), were housed under temperature and light controlled conditions $\left(23^{\circ} \mathrm{C}, 12 \mathrm{~h}\right.$ light $/ 12 \mathrm{~h}$ dark cycle). Rats were acclimated at least one week after their arrival to animal facility and assigned to control or sensorimotor perturbation (SMP) group arbitrarily, no randomization methods were applied. They had ad libitum access to water and food and were regularly handled. Body weight was monitored 3 days/week.

\section{Model of sensorimotor perturbation}

SMP was induced by hindlimb unloading, which was performed using tail suspension model during 14 days (Morey-Holton and Globus 2002). The rats were introduced in a rodent restrain device (Harvard Apparatus rodent) which ensured free access to the tail. The latter was gently washed, dried and then disinfected with alcohol $\left(30^{\circ}\right)$. An elastic adhesive tape (Tensoplast, BSN Medical) was then applied to the proximal third of the tail to allow the maintenance of thermoregulation. Its stretching was kept to a minimum so as not to impede blood circulation. The upper end of the adhesive strip was then connected to a swivel system that can lift the posterior train of the rat and ensured $360^{\circ}$ movements. Total duration of this procedure did not exceed $5 \mathrm{~min}$. The height was adjusted to obtain a $30^{\circ}$ inclination of rat body with horizontal. The posterior train of the animal was lifted progressively in 3 stages separated by one hour each. The forelimbs remaining in contact with the ground allowed rats to walk freely on their forelimbs and to have free access to water and food. SMP rats were arranged next to each other and could have social interactions with their neighbors, and $C$ animals were housed 2 per cage. The criteria for inclusion/exclusion were based on the health state of animal. The animal that showed any sign of tail necrosis, porphyrin around the eyes and nose beyond the first two days of SMP, reduction or absence of food intake and/or excessive body weight loss (>15\%) were excluded. 
In order to evaluate the time-course of synaptic plasticity induced by a period of SMP and during a

\section{Tissue sampling}

For tissue sampling, rats were deeply anesthetized through intraperitoneal injection of sodium pentobarbital ( $80 \mathrm{mg} / \mathrm{kg}$, Ceva Animal Health). Deep anesthesia level was checked by suppression of paw withdrawal reflex. Then, thoracic cavity was open to allow access to the heart. Intracardiac infusion of ice-cold solution of $\mathrm{NaCl} 0.9 \%$ was then performed until total exsanguination. Then, the head of the animal was fixed in a stereotaxic frame, the skin incised and a craniotomy was performed to expose cerebral cortex. The dura-mater was resected. A sample of sensorimotor cortex was taken at stereotaxic coordinates anterior 0 to -2 and lateral 2 to 4 , corresponding to display area of the hindlimb. Samples were placed in liquid nitrogen and stored at $-80^{\circ} \mathrm{C}$. Total duration of sampling did not exceed 5 min.

\section{Enrichment in synaptic proteins}

This protocol was based on our previous study (Fourneau et al. 2020). Briefly, frozen brain samples were homogenized on wet ice using ice-cold HEPES buffer (145mM NaCl, $5 \mathrm{mM} \mathrm{KCl}, 2 \mathrm{mM} \mathrm{CaCl}_{2}, 1 \mathrm{mM}$ $\mathrm{MgCl}_{2}, 5 \mathrm{mM}$ glucose, 5mM HEPES, $50 \mu \mathrm{M}$ PUGNAc, protease and phosphatase inhibitors, pH7.4) containing $0,32 \mathrm{M}$ sucrose. The initial homogenate was centrifuged at $600 \times \mathrm{g}$ for $10 \mathrm{~min}$ at $4^{\circ} \mathrm{C}$. The supernatant was then diluted 1:1 with 1.3M sucrose in HEPES buffer, to yield a suspension at a final concentration of $0.8 \mathrm{M}$ sucrose in HEPES buffer. This suspension was further centrifuged at $20000 \mathrm{xg}$ for $30 \mathrm{~min}$. The supernatant was collected (light membranes and soluble enzymes fraction); the pellet (synaptic proteins enriched fraction) was centrifuged for 2 to 3 times at $12000 \times g$ for $15 \mathrm{~min}$ (series of washes with HEPES buffer). The crude synaptosomal fraction was resuspended in RIPA buffer $(10 \mathrm{mM}$ Tris $\mathrm{HCl}, 150 \mathrm{mM} \mathrm{NaCl}, 1 \mathrm{mM}$ EDTA, 0,2\% Triton X-100, $0.5 \% \mathrm{Na}$ + deoxycholate, $0.1 \%$ SDS, pH7.4). Protein concentration of the supernatant was determined by a Bradford assay (Biorad).

\section{SDS-PAGE and western blot analysis}

Synaptic proteins fraction (previously boiled in Laemmli buffer) were resolved by SDS-PAGE. Proteins were separated on $7.5 \%$ or $10 \%$ polyacrylamide gels (TGX Stain-Free ${ }^{\mathrm{TM}}$ FastCast $^{\mathrm{TM}}$ Acrylamide Kits, Biorad). Stain-Free technology contains a proprietary trihalo compounds which react with proteins, rendering them detectable with UV exposures. Stain-Free imaging was performed using ChemiDoc MP Imager (Biorad) and Image Lab 4 software (Biorad) with a 2.5 min stain activation time, and total protein images were therefore obtained. Proteins were then transferred to $0.2 \mu \mathrm{m}$ nitrocellulose sheet (Trans-Blot ${ }^{\circledR}$ Turbo ${ }^{\mathrm{TM}}$ RTA Midi Nitrocellulose Transfer Kit, cat\# 1704271, Biorad) using TransBlot Turbo Transfer System (Biorad). The quality of transfer was controlled by imaging membranes using Stain-Free technology. Membranes were then washed in TBST $(15 \mathrm{mM}$ Tris/HCl, pH 7.6; $140 \mathrm{mM}$ $\mathrm{NaCl} ; 0.05 \%$ Tween-20) and blocked in $5 \%$ non-fat dry milk or BSA in TBST. Membranes were then blotted in blocking solution overnight at $4^{\circ} \mathrm{C}$ with primary antibodies (Table 1). After $3 \times 10 \mathrm{~min}$ washes in TBST, membranes were probed with specific secondary antibodies (1:5000, Anti-rabbit IgG, 
HRP-linked Antibody, Cell Signaling Technology, \#7074, and Anti-mouse IgG, HRP-linked Antibody, Cell Signaling Technology, \#7076) in blocking solution for $2 \mathrm{~h}$ at room temperature, and finally extensively washed in TBST. All experimental procedures, such as blocking solutions as well as dilutions of primary and secondary antibodies were optimized for each antibody. Chemiluminescence detection was carried out using ECL Clarity (Clarity ${ }^{\mathrm{TM}}$ Western ECL Substrate, Biorad), and images capture were done with ChemiDoc MP. All images were analyzed using Image Lab 4 software. Normalization of protein signal intensities was carried out following quantification of respective total protein level on Stain-Free images. Whether membranes needed to be reprobed to use another antibody, stripping membrane was performed using Western reprobe (G-Biosciences). Phosphospecific signal was normalized to total signal in order to estimate activated marker ratio. Total signal was normalized to Stain-Free staining, which reveals total protein profile of each sample.

Table 1: List of primary antibodies

\begin{tabular}{|c|c|c|}
\hline Primary antibody & Reference & Dilution \\
\hline \multicolumn{3}{|c|}{ Presynaptic proteins } \\
\hline Phospho-synapsin 1 (ser62/67) & Merck Millipore Ab9848 & $1: 1000$ \\
\hline Synapsin 1 & Merck Millipore Ab1543 & $1: 20000$ \\
\hline Synaptophysin & Cell Signaling Technology \#4329 & $1: 2000$ \\
\hline Synaptotagmin 1 (D33B7) & Cell Signaling Technology \#14558 & $1: 2000$ \\
\hline \multicolumn{3}{|c|}{ Postsynaptic proteins } \\
\hline Phospho-AMPA Receptor (GluA2) (ser880) & Merck Millipore MABN103 & $1: 1000$ \\
\hline $\begin{array}{l}\text { Phospho-AMPA Receptor (GluA2) } \\
\text { (tyr869/tyr873/tyr876) }\end{array}$ & Cell Signaling Technology \#3921 & $1: 1000$ \\
\hline AMPA Receptor (GluA2) (D39F2) & Cell Signaling Technology \#5306 & $1: 2000$ \\
\hline Phospho-AMPA Receptor (GluA1) (ser845) & Cell Signaling Technology \#8084 & $1: 1000$ \\
\hline AMPA Receptor (GluA1) (D4N9V) & Cell Signaling Technology \#13185 & 1:2000 \\
\hline Phospho-NMDA Receptor 1 (GluN1) (ser897) & Cell Signaling Technology \#3385 & $1: 1000$ \\
\hline NMDA Receptor (GluN1) (D65B7) & Cell Signaling Technology \#5704 & $1: 2000$ \\
\hline \multicolumn{3}{|c|}{ Scaffolding protein } \\
\hline PSD-95 & Cell Signaling Technology \#2507 & $1: 2500$ \\
\hline \multicolumn{3}{|c|}{ Trans-synaptic adhesion protein } \\
\hline N-cadherin & Cell Signaling Technology \#4061 & 1:1000 \\
\hline \multicolumn{3}{|c|}{ Cytoskeleton proteins } \\
\hline Neurofilament-L (C28E10) & Cell Signaling Technology \#2837 & $1: 2000$ \\
\hline Neurofilament-M (RMO 14.9) & Cell Signaling Technology \#2838 & $1: 2000$ \\
\hline
\end{tabular}

\section{Statistical analysis}

Results are presented as mean \pm SEM. The normality of each group was evaluated by the Kolmogorov-Smirnov's test. The groups were compared by an ANOVA followed by a Holm-Sidak's multiple comparison post-hoc test. Non-normally distributed datasets are tested by non-parametric Kruskal-Wallis test followed by a Dunn's multiple comparison post-hoc test. To determine whether SMP affected the expression of proteins and if values were restored after 24 hours of recovery, SMP (D1 to D14) and recovery (R6 and R24) groups were compared to control group (D0) and recovery groups (R6 and R14) to the end of SMP (D14). The level of significance is set at $p<0.05$. 


\section{Results}

\section{Presynaptic plasticity}

In order to evaluate the evolution of presynaptic plasticity during a period of SMP and a recovery phase, the phosphorylation and expression of proteins located on the synaptic vesicles and actively involved in different stages of their mobilization for neurotransmitter release were determined by western blotting (Figure 1). Synapsin1 regulates neurotransmitter release, synaptophysin is a marker for presynaptic terminal activity and synaptotagmin1 is the major vesicular $\mathrm{Ca}^{2+}$ sensor involved in neurotransmitters exocytosis (Bacaj et al. 2015; Bogen et al. 2006; Nithianantharajah et al. 2004).

At D1, no change was observed except for synaptophysin expression, which was increased $(+36 \%$, $\mathrm{p}<0.001)$. After 14 days of SMP, total expression and phosphorylated form of synapsin 1 were significantly decreased in the sensorimotor cortex $(-29 \%, p<0.05$ and $-41 \%, p<0.05$ respectively) (Figure 1a and 1b). Moreover, we can observe a progressive and particularly marked decrease of the total expression of synaptophysin $(-60 \%, p<0,0001)$ (Figure 1c) and synaptotagmin1 $(-36 \%, p<0.001)$ (Figure 1d).

The decrease in the total expression of the three presynaptic markers was maintained during the recovery phase. Values at R24 were lower than C ones (synapsin1: $-50 \%, p<0.001$; synaptophysin: $90 \%, p<0.0001$; and synaptotagmin1: $-34 \%, p<0.01$ ) and similar to D14 values or even lower (synaptophysin: $-75 \%, \mathrm{p}<0.05$ ).

To sum up, the total expression of synapsin1, synaptophysin, and synaptotagmin 1 decreased gradually during the SMP period and do not recover, which could result in a decrease in the availability and/or mobilization of synaptic vesicles, even during the recovery period. 


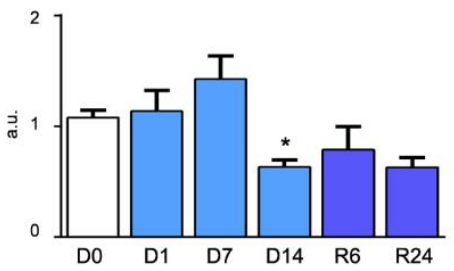

(C) Synaptophysin
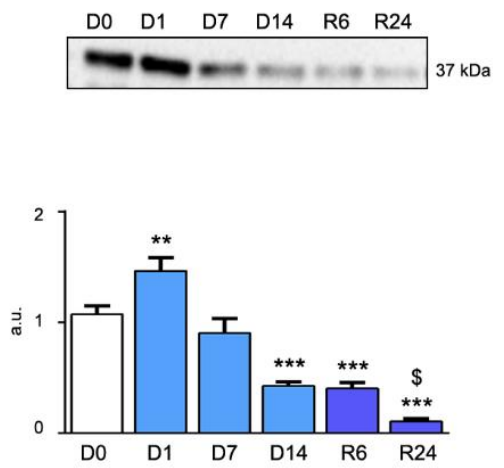

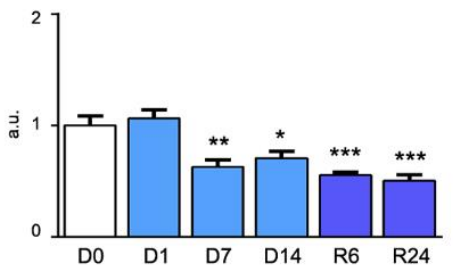

(D) Synaptotagmin 1
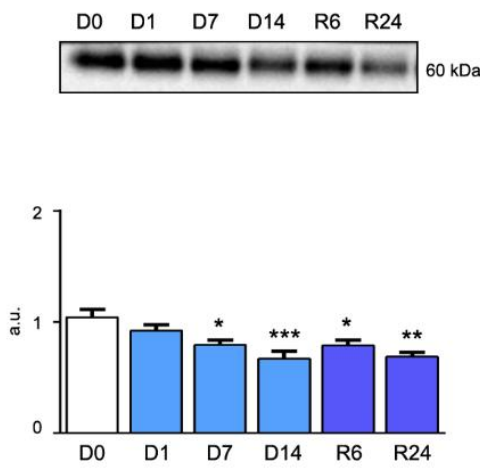

Figure 1. Phosphorylation and total expression of presynaptic proteins after 1, 7 and 14 days of SMP and after $\mathbf{6 h}$ and $\mathbf{2 4} \mathrm{h}$ of recovery. Representative Western blot and quantification of ser62/67 phosphorylation of synapsin 1, and total expression of synapsin 1, synaptophysin, and synaptotagmin 1 (normalized to whole proteome, i.e. Stain Free signal). ${ }^{*}, *$, and ${ }^{* * *}$ correspond respectively to $p<0.05, p<0.01$, and $p<0.001$ relative to D0; $\$$ corresponds to $p<0.05$ with respect to D14. a.u.: arbitrary unity.

\section{Postsynaptic plasticity}

At the postsynaptic level, AMPARs are generally known to mediate rapid excitatory synaptic transmission in the central nervous system whereas NMDAR are involved in activation of different signaling pathways that regulate synaptic force (MacDermott et al. 1986). To determine the evolution of AMPAR and NMDAR trafficking regulation during a SMP period and the recovery phase, the phosphorylation and expression levels of GluA1 and GluA2 subunits of AMPAR and GluN1 subunit of NMDAR were determined by western blotting (Figure 2).

The phosphorylation level of the GluA2 subunit on tyr869, tyr873, tyr876 (3-tyr) and ser880 are indicators of the traffic process of AMPAR (Yong et al. 2020). No change was noticed in the early stage (from D1 to D7) of SMP. At D14, p-3-tyr and p-ser880 on GluA2 subunit were increased $(+76 \%$, $\mathrm{p}<0.05$ and $+69 \%, p<0.05$ respectively) (Figure $2 \mathrm{a}-\mathbf{b}$ ). At the opposite, the total expression of AMPAR GluA2 was decreased after 14 days of $\operatorname{SMP}(-51 \%, p<0.05)$ (Figure $2 \mathrm{c}$ ). During the recovery phase, values remained similar to D14 ones. 
The phosphorylation of the ser845 of the GluA1 subunit is involved in the insertion of this subunit at postsynaptic density. The p-ser845 did not vary significantly during a SMP period nor in the recovery phase (Figure 2d). In contrast, the total expression of AMPAR GluA1 decreased progressively and reached significance at R24 $(-25 \%, \mathrm{p}<0.05)$ (Figure 2e).

NMDAR are heterotetramer consisting of two GluN1 subunits and a combination of GluN2 and/or GluN3 subunits. Phosphorylation of Ser-897 on GluN1 promotes the release of the receptor from endoplasmic reticulum to plasma membrane. After a transient decrease at D7, the p-ser896 increased at D14 $(+26 \%, p<0.05)$ and remained elevated during the recovery period (Figure $2 \mathrm{f})$. At the opposite, GluN1 total expression decreased $(-34 \%, p<0.01)$ (Figure $2 \mathrm{~g}$ ) after 14 days of SMP and control values were restored as soon as after $6 \mathrm{~h}$ of recovery.

To sum up, the total expression of both receptors decreased during a SMP period while phosphorylation level was increased, suggesting changes in receptor trafficking. These changes persisted during the $24 \mathrm{~h}$ of recovery, except for the total NMDA receptor level. 
(A) P-AMPAR GluA2 (3-tyr)

$\begin{array}{llllll}\text { D0 } & \text { D1 } & \text { D7 } & \text { D14 } & \text { R6 } & \text { R24 }\end{array}$

(B) P-AMPAR GluA2 (ser880)

$\begin{array}{llllll}\text { D0 } & \text { D1 } & \text { D7 } & \text { D14 } & \text { R6 } & \text { R24 }\end{array}$

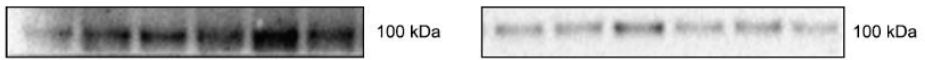
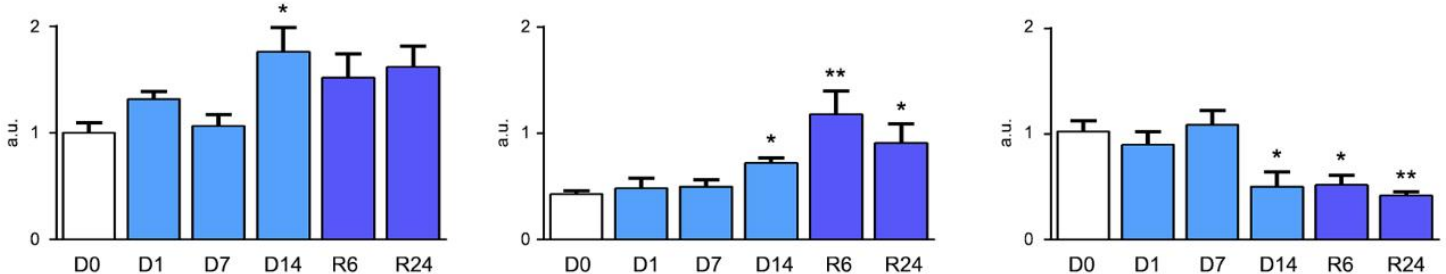

(D) P-AMPAR GluA1 (ser845)

(E) AMPAR GluA1

$\begin{array}{llllll}\text { D0 } & \text { D1 } & \text { D7 } & \text { D14 } & \text { R6 } & \text { R24 }\end{array}$

$\begin{array}{llllll}\text { D0 } & \text { D1 } & \text { D7 } & \text { D14 } & \text { R6 } & \text { R24 }\end{array}$
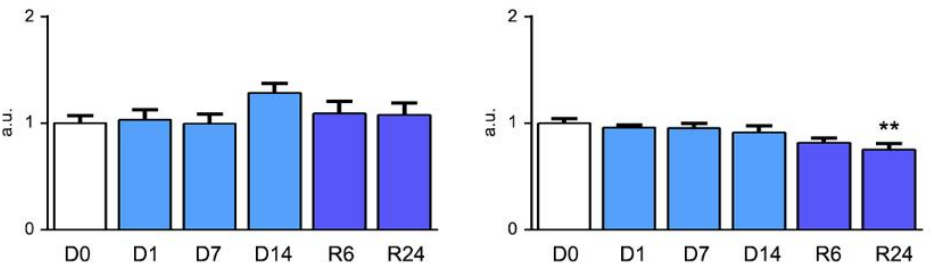

(F) P-NMDAR GluN1 (ser897)

(G) NMDAR GluN1

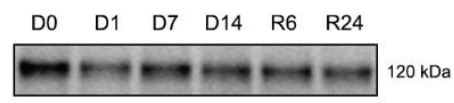

$\begin{array}{llllll}\text { D0 } & \text { D1 } & \text { D7 } & \text { D14 } & \text { R6 } & \text { R24 }\end{array}$
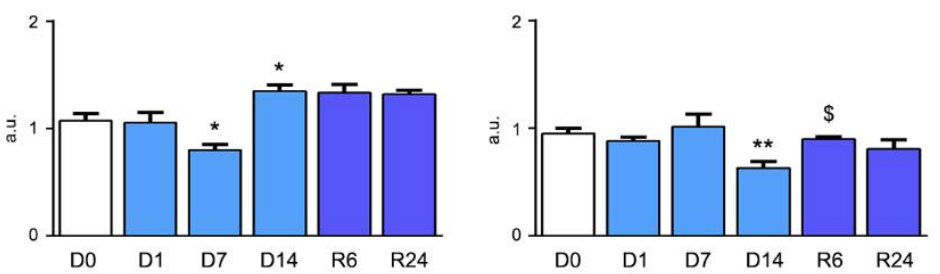

Figure 2: Phosphorylation and total expression of ionotropic glutamate receptor subunits after 1, 7 and 14 days of SMP and after $6 \mathrm{~h}$ and $24 \mathrm{~h}$ of recovery. Representative Western blots and quantification of tyr869/tyr873/tyr876 and ser880 phosphorylation of AMPAR GluA2, total AMPAR GluA2 expression, AMPAR GluA1 ser845, AMPAR GluA1 expression, NMDAR1 ser897 phosphorylation and NMDAR1 expression. C, E and G were normalized to whole proteome, i.e. Stain Free signal. * and ** correspond respectively to $p<0.05$ and $p<0.01$ with respect to D0. $\$$ corresponds to $p<0.05$ with respect to D14. a.u.: arbitrary unity. 


\section{Scaffolding and trans-synaptic adhesion proteins}

Scaffolding proteins, such as PSD-95, and adhesion molecule, such as N-cadherin, are determinant for structuring pre- and post-element of synapse, and are as also important for the AMPAR and NMDAR trafficking (Cousins et al. 2008; Schnell et al. 2002; Stan et al. 2010). The total expressions of PSD-95 and N-cadherin were thus determined by western blotting during SMP and a recovery phase (Figure 3).

Expression of PSD-95 was decreased $(-33 \%, \mathrm{p}<0.01)$ after 14 days of SMP (Figure 3a). During the recovery period, values were intermediate between D0 and D14 values.

$\mathrm{N}$-cadherin expression was decreased at D14 $(-29 \%, \mathrm{p}<0.05)$. The decrease was followed by a recovery as soon as 6 hours after the sensorimotor activity was resumed (Figure $\mathbf{3 b}$ ).

Thus, the changes in scaffold and adhesion proteins suggest a reworking in the postsynaptic density during SMP and recovery as well as a decrease of the contact between pre- and postsynaptic elements.

(A) PSD-95

$\begin{array}{llllll}\text { D0 } & \text { D1 } & \text { D7 } & \text { D14 } & \text { R6 } & \text { R24 }\end{array}$
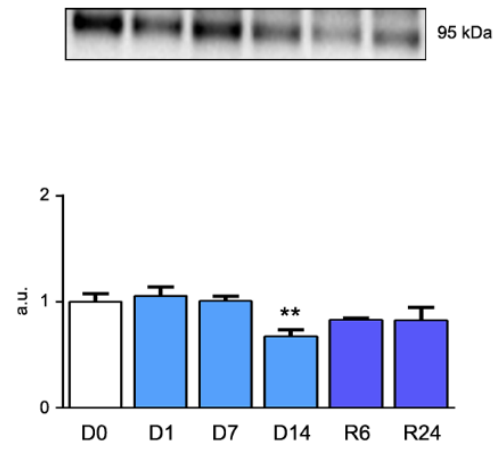

(B) N-cadherin
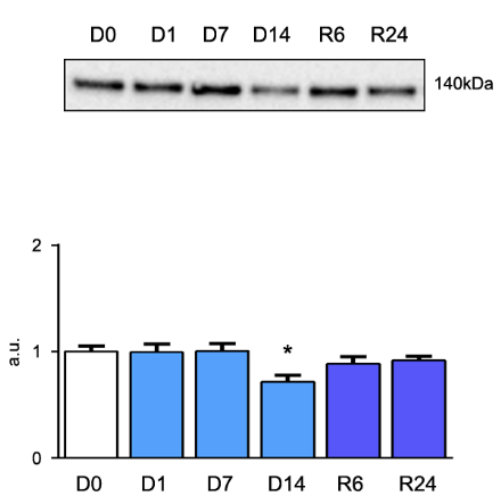

Figure 3: Total expression of scaffolding and trans-synaptic adhesion proteins after 1,7 and 14 days of SMP and after $\mathbf{6 h}$ and $\mathbf{2 4 h}$ of recovery. Representative Western blots and quantification of PSD-95 and $\mathrm{N}$-cadherin expression (normalized to whole proteome, i.e. Stain Free signal). ${ }^{*}$ and ${ }^{* *}$ correspond respectively to $p<0.05$ and $p<0.01$ with respect to D0. a.u.: arbitrary unity.

\section{Dynamics of the cytoskeleton}

Cytoskeletal proteins such as actin, tubulin, or neurofilaments (NF) are the major constituents of preand postsynaptic elements, making the link between many proteins. New evidence points to an important role for the L (light) and M (medium) NF subunits in neurotransmission by influencing the traffic of synaptic vesicles and especially at the postsynaptic level in the traffic of receptors such as NMDAR GluN1 or dopamine D1 receptor (Yuan et al. 2017; Yuan et al. 2018). To study the dynamics of the synaptic cytoskeleton during a period of SMP and a recovery phase, the total expression levels of the NF-L and M were determined (Figure 4). 
The expression of NF-M was increased in the earliest phase of SMP (D1: $+67 \%, p<0.01$; D7: $+50 \%$, $p<0.05)$. At D14, the total expression of NF-L $(-44 \%, p<0.001)$ (Figure 4a), NF-M $(-50 \%, p<0.05)$ (Figure 4b). A progressive recovery was noticed at R6 and R24 for NF-L and NF-M.

Thus, taken together, these results indicate that the cytoskeleton proteins appear to be regulated differently during a period of SMP and a recovery phase.

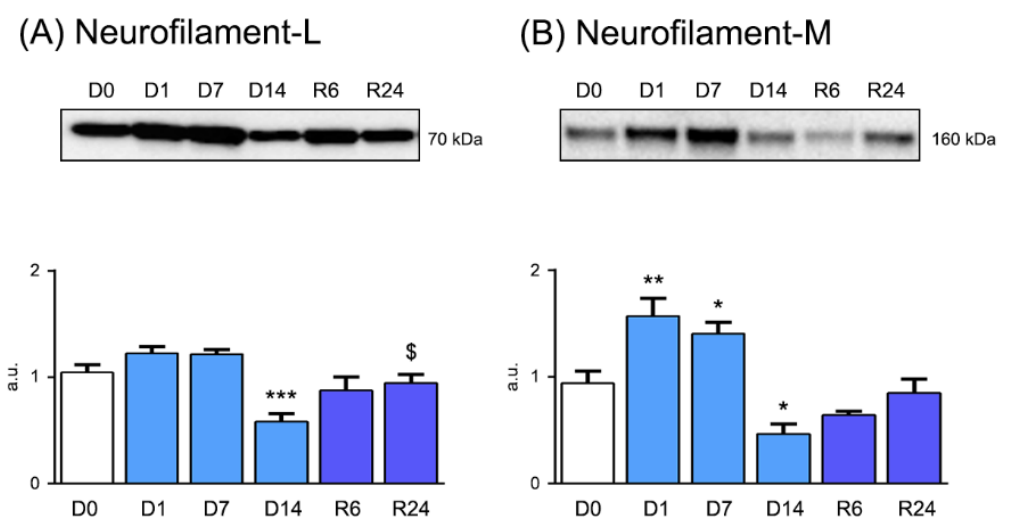

Figure 4: Total expression of cytoskeletal proteins after 1, 7 and 14 days of SMP and after $6 \mathrm{~h}$ and 24h of recovery. Representative Western blots and quantification of NF-L and NF-M expression (normalized to whole proteome, i.e. Stain Free signal). ${ }^{*}$ and ${ }^{* *}$ correspond respectively to $p<0.05$ and $p<0.01$ with respect to d0; $\$$ corresponds to $p<0.05$ with respect to d14. a.u.: arbitrary unity. 


\section{Discussion}

Table 2: Summary table. Changes in expression and activation of the different classes of synaptic proteins during a sensorimotor perturbation (D0, D1, D7, D14) and during a recovery phase (R6 and R24). Red: decrease; green: increase.

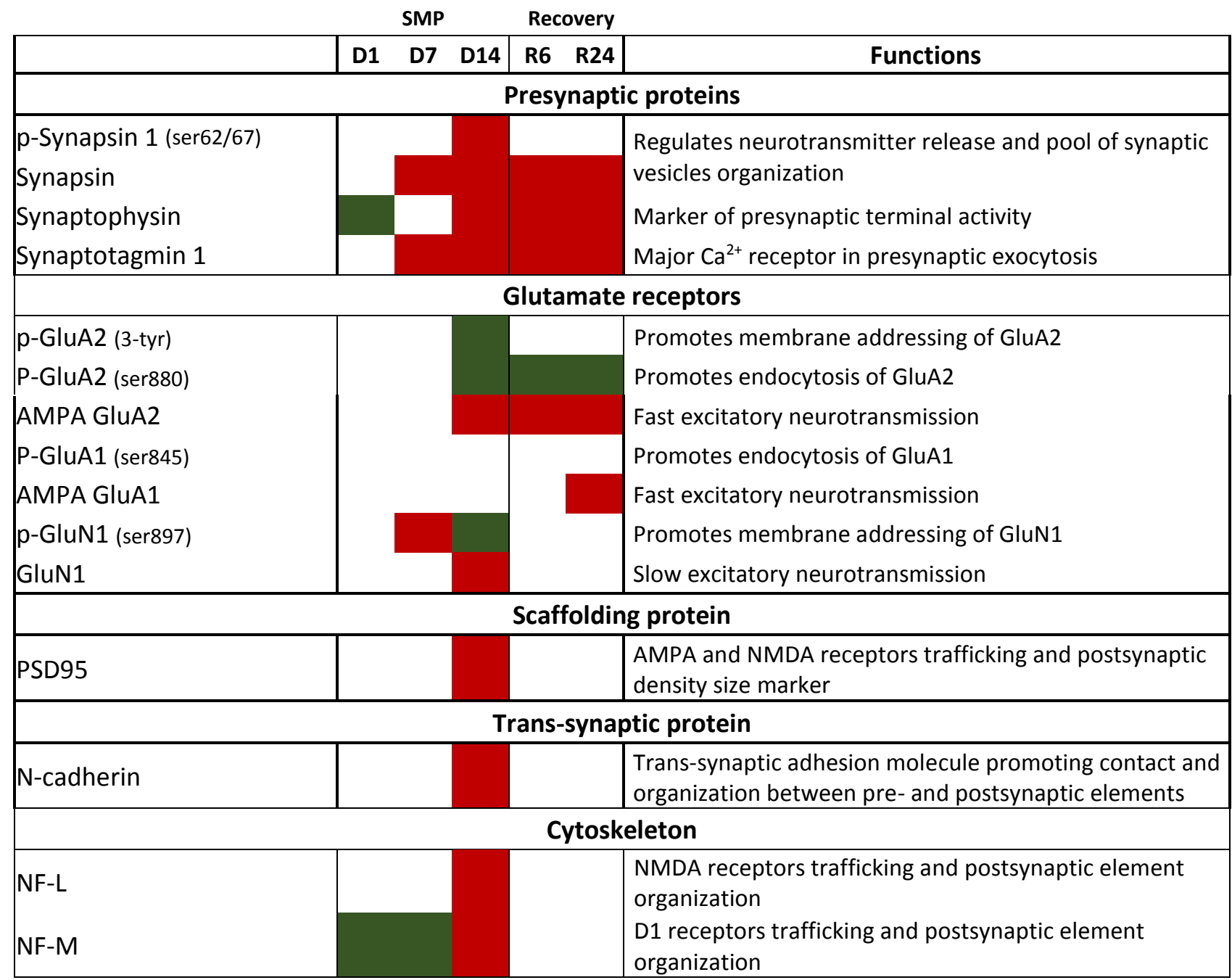

The main objective of this study was to observe the time-course of activation and expression of several proteins involved in synaptic transmission during a sensorimotor perturbation period and a recovery phase. The study was performed in adult rats, i.e. at a period where expression levels of synaptic proteins do not spontaneously show the rapid and important changes that can be observed during childhood and adolescence (Shiotani et al 2017). These data are summarized in Table 2. They show that the pre- and postsynaptic molecular dynamics are impacted during a period of SMP. Our main results are as follows. First, most changes were observed as soon as D7 in the presynaptic compartment. They were followed, at D14, by changes in the postsynaptic compartment (glutamate receptors). These changes persisted at least until $24 \mathrm{~h}$ of recovery. Second, proteins involved in synapse structure (scaffolding, adhesion, cytoskeletal proteins) were mildly affected with respect to pre- and postsynaptic proteins, and almost exclusively at D14. Third, there was almost no change in the earliest phase of SMP (at D1). Fourth, for some proteins (NF-M, synaptophysin and p-GluN1), opposite effects were observed at D7 and later. 
First changes appear within the intermediate phase (D7). They were mainly focused on the presynaptic compartment. The expression of synapsin 1 and synaptotagmin 1 decreased in the sensorimotor cortex, whereas synaptophysin increased. These three proteins are located on the synaptic vesicles and are important for each stage of the neurotransmitter release cycle. A decrease in the expression of synapsin 1 reflect changes in the availability of synaptic vesicles (Bogen et al. 2006; Nithianantharajah et al. 2004), while a decrease in synaptotagmin 1 reduces release capacities of synaptic vesicles from the active area (Bacaj et al. 2015). Thus, it can be considered that SMP induces a reduction in availability and release of synaptic vesicles in the presynaptic endings of cortical sensorimotor neurons. Synaptophysin is a highly abundant protein localized on synaptic vesicles. Thus, it is often used as a marker of presynaptic terminals. Previous studies have highlighted diverse roles for synaptophysin in synaptic vesicles cycle (endocytosis/exocytosis) (Kwon and Chapman 2011; Raja et al. 2019). Our data suggest that SMP modulates the synaptic vesicles endocytosis and/or exocytosis cycling.

At the postsynaptic level, the total expression of AMPAR GluA2 was decreased. Since AMPARs are known to mediate rapid excitatory synaptic transmission in the CNS, this result suggests an impairment in synaptic transmission (Diering and Huganir 2018). We also examined the essential NMDAR subunit GluN1. NMDAR are involved in some forms of information storage at synapses. The total expression of GluN1 decreased, suggesting as well a change in excitatory neurotransmission as well as activity-dependent synaptic plasticity in the sensorimotor cortex (Cull-Candy and Leszkiewicz 2004).

Synaptic efficacy depends not only on the total number of receptors, but also on the proportion of receptors incorporated into the postsynaptic membrane. Internalization vs membrane anchoring of receptors is dependent on their phosphorylation level. The higher phosphorylation of ser880 (Chung et al. 2000; Steinberg et al. 2006) on GluA2 subunit suggests that internalization of AMPA receptor was increased at D14. Such an increased endocytosis of GluA2 AMPARs also occurs during LTD, leading to a decrease in AMPARs at the postsynaptic surface (Seidenman et al. 2003). Interestingly, we can observe at D14 an increase of the 3-tyr phosphorylation which leads to the membrane addressing of GluA2 (Hayashi and Huganir 2004; Yong et al. 2020). It has been shown that the tyr876 site, but not tyr873 and tyr869, is necessary for homeostatic plasticity but not for Hebbian plasticity (Yong et al. 2020). This opposite effect between the ser880 and 3-tyr phosphorylation can show the very fast modulation of AMPA receptors expression on the surface of the postsynaptic membrane. The increased phosphorylation of GluN1 on ser896 further supports this idea. Simultaneous phosphorylation of ser896 and ser897 is necessary to increase the number of NMDARs on the membrane surface (Scott et al. 2001). Although the phosphorylation of ser897 is unknown, we can formulate the hypothesis that the increased phosphorylation of ser896 compensates for the decreased expression.

It should be mentioned that changes in glutamate receptors occurred later than changes in exocytosis mechanisms. The lower exocytosis of neurotransmitters might be the origin of postsynaptic changes, consistently with the Hebbian mechanism of synaptic plasticity.

\section{Proteins involved in synapse structure are mildly affected}

Scaffold, adhesion and cytoskeletal proteins are important regulators of synapse structure. A decrease of $\mathrm{N}$-cadherin is observed. The localization of $\mathrm{N}$-cadherin to pre- and postsynaptic structures permits to stabilize and maintain synaptic contact. At the presynaptic level, $\mathrm{N}$-cadherin is a 
key player in the control of presynaptic vesicle clustering (Stan et al. 2010). Decreased N-cadherin observed at D14. Indeed, we observed a decrease in the phosphorylation of ser62/67 of synapsin 1 , as well as a decrease in the expression of synapsin 1 , synaptophysin and synaptotagmin 1 . These results show that the availability and/or mobilization of the vesicles are reduced during a period of SMP. At the postsynaptic level, in addition to the phosphorylation status of receptor subunits, the decrease in expression of these two glutamate receptors may be linked to a series of events, including the decrease in expression of N-cadherin and PSD-95. Indeed, PSD-95 regulates, directly or not, the traffic and stabilization of AMPA and NMDA receptors at postsynaptic density (Cousins et al. 2008; Schnell et al. 2002). Then, the number of AMPAR is correlated with the expression of PSD-95 during LTP (Ehrlich and Malinow 2004). Conversely, a deletion of PSD-95 by a Knock-Down leads to a reduction in the number of AMPARs as well as a decrease in the currents of AMPAR and NMDAR (Ehrlich et al. 2007; Ehrlich and Malinow 2004; Futai et al. 2007). Then, the reduction of the glutamate receptors can be linked indirectly to the expression of the $\mathrm{N}$-cadherin. Indeed, an ablation of N-cadherin leads to a decrease of PSD-95 (Nikitczuk et al. 2014).

A final possibility is the role of the cytoskeleton in the targeting and stabilization of proteins such as PSD-95 or GluN1 NMDARs at the postsynaptic density. Cytoskeletal proteins such as NF may be involved in the localization of glutamate receptors. The NF of mature neurons are among the most abundant proteins in the brain. However, their role at the synaptic level remains a mystery since synapses have long been considered as sites of degradation for neurofilaments reaching the endings. NF-L is known to interact with the GluN1 subunit of NMDAR. It selectively influences its localization and stabilization at the postsynaptic density membrane and is essential for the proper functioning of this receptor (Ehlers et al. 1998; Yuan et al. 2018). Thus, the marked decrease in NF-L at D14 is consistent with a lower membrane anchoring of these receptors, and in consequence, to an altered synaptic efficacy. Taken together, these results reinforce the hypothesis of an increase in the internalization of receptors during SMP.

PSD-95 is frequently used as a molecular marker to determine the size and strength of synapses (Holtmaat and Svoboda 2009). Overexpression of PSD-95 is observed at postsynaptic density during LTP and is associated with an increase in head volume, while deletion of PSD-95 is associated with a decrease in the number of dendritic spines in the brain, striatum and hippocampus (Vickers et al. 2006). N-cadherin regulates spine dynamics and stability as well (Wang et al. 2013). Indeed, an acute interference of the functional role of $\mathrm{N}$-cadherin promotes spine motility followed by decrease in spine length and spine loss (Mysore et al. 2007). At the cytoskeleton level, NF-L are also important for the structure and stability of dendritic spines, both at the pre- (synaptic vesicle bond) and postsynaptic (organization of postsynaptic density) levels. In NF-L -/- mice for instance, a reduction in dendritic spine length and density was observed (Yuan et al. 2018). Thus, the decrease in expression of PSD-95, N-cadherin and NF-L may influence spine density and/or morphology in SMP rats. In a previous study, we have provided evidence for a slightly increase in spine density on pyramidal neurons. As for the spine morphology, the size of the head was reduced for the pyramidal neurons of the infragranular layers after SMP, and spine length was lower, whatever the spine category (Trinel et al. 2013). These morphological changes in dendritic spine structure might be, at least in part, linked to the decrease in the expression of PSD-95, N-cadherin and NF-L.

\section{SMP has almost no effect at very short term (D1) although recovery occurs very quickly.}

The paucity of effect of SMP at very short term (D1) follows the absence of cortical maps reorganization (Dupont et al. 2001; Langlet et al. 1999) but not the changes observed in neuronal activity. Indeed, both afferent (L5 neurogram) and efferent activities (soleus EMG) from and to the 
hindlimb are strongly reduced, at least during the first week of SMP, and are even almost silent at D1 (Alford et al. 1987; De-Doncker et al. 2005). It is known that the neuronal activity induces a significant mobility of AMPAR (lateral diffusion, endo-exocytosis) and to a lesser extent NMDARs on the surface of the synaptic membrane (Groc et al. 2004). This mechanism, observed in vitro (culture of cortical neurons) (Ehlers 2000), occurs very quickly since it is observed as soon as 2 min after TTX activity blockade (Ehlers 2000).

The absence of changes at D1 was unexpected since dendritic spines can also evolve remarkably quickly (in a few seconds to a few minutes) (Holtmaat and Svoboda 2009). Unfortunately, we have no data about dendritic spines within the first day of SMP, the morphological analysis of dendritic spines was only performed after 14 days of SMP (Trinel et al. 2013). However, as explained above, the scaffolding (PSD-95) or the cytoskeleton (NF-L) proteins involved in synaptic morphology did not present any variation at D1 nor D7. The turnover and changes in morphology of the dendritic spines highly depend on the type of change in sensory experience as well as the age of the animals (Fu and Zuo 2011).

In the present study, we only observed an increase in NF-M (D1 to D7). NF-M are very abundant in postsynaptic endings and a recent model suggests that the role of NF-M is to anchors D1-receptorcontaining endosomes within synapses (Yuan et al. 2017). Dopamine receptor are abundant within the sensorimotor cortex (Gu 2002) but their role in synaptic plasticity has not been established so far.

We noticed that protein changes are transient and reversible, with a very short recovery time-course (about 6h) for most proteins (GluN1, PSD95, NF-L, N-cadherin...). That contrasts with the rather long duration of apparition of changes during SMP. However, it follows then immediate reversibility for cortical maps. Indeed, 6 hours are sufficient to restore the size of the cortical representation of the hindpaw (Dupont et al. 2001; Langlet et al. 1999). These results suggest that the return to the initial state does not involve induction of a new adaptative mechanism in response to a sudden increase in sensorimotor activity, but rather corresponds to a return to the initial pattern. In other words, the "SMP configuration" of synapses was not stabilized.

\section{Protein expression can evolve differently at D7 and D14.}

For a few parameters, opposite effects were observed at short and long term, i.e. increase at D7 and decrease at D14 (synaptophysin, NF-M) or decrease at D7 and increase at D14 (p-GluN1). This effect can be related to neuronal activity, which has been shown to be profoundly depressed the first week of SMP but paradoxically was increased within the second week (Alford et al. 1987; De-Doncker et al. 2005).

This effect can be explained by the fact that neuronal circuits have the capacity to maintain relatively constant activity in response to perturbations (i.e. sensorimotor perturbation) that alter excitability or synaptic properties (Cunningham and Littleton 2019). For example, reductions in postsynaptic receptor function can be offset by increasing presynaptic output through a process known as presynaptic homeostatic potentiation (Böhme et al. 2019; Cunningham and Littleton 2019; Reid et al. 2003). We can therefore observe a phasic activity-dependent neuronal plasticity, where at an early stage D7, the observed results would be a compensation to maintain the "normal" activity of the neuronal circuit. While later, after D14, this compensation cannot be maintained and neuronal excitability decreases. 
As mentioned above, some changes in the expression of glutamate receptors, in particular AMPA ones, are consistent with a Hebbian mechanism of synaptic plasticity. In other words, Hebbian and non-hebbian (homeostatic) mechanisms may coexist. In fact, both types of plasticity partially share common mechanisms; AMPA receptor exocytosis/endocytosis may be the critical interaction point between them (Li et al. 2019).

In this study, we were particularly interested in the evolution of the glutamatergic system and the AMPA and NMDA receptors. However, it has been shown that the reorganization of somatosensory cortical maps is jointly regulated between the glutamatergic and GABAergic systems (Benali et al. 2008). The neurotransmitter GABA is thought to be involved in the masking of horizontal connections and consequently in the rapid reorganization of cortical maps (Xerri 2008). Thus, a change in cortical GABA levels, such as the decrease observed following 14 days of SMP (Canu et al. 2006), could have an influence on the strength of horizontal excitatory connections through lack of inhibitory control. Further studies are needed to elucidate the importance of the GABAergic system in the reorganization of the somatosensory cortex following SMP.

\section{Conclusion}

As a whole, changes in synaptic proteins described in the present article follow the same time-course as cortical maps: our previous studies have demonstrated that cortical characteristics were unchanged after 1 day of SMP, then a disorganization occurred on the 7th day and finally a decrease in this somatotopic area was well-established on the 14th day (Dupont et al. 2001). In addition, a rapid recovery was observed as soon as $6 \mathrm{~h}$ after the end of SMP. However, several proteins remained affected at D24. At the presynaptic levels, results suggest that the availability and/or mobilization of the vesicles do not return to normal after 1 day of recovery. At the postsynaptic level, glutamate neurotransmission remains altered (lower level of AMPAR GluA1 and GluA2 subunits, increased phosphorylation level of GluA2 Ser880). Thus, the question that arises is whether cortical map reorganization is sustained by changes in synaptic proteins. No study has looked at the involvement of glutamatergic receptors in the shrinkage of sensory cortical maps in our model of SMP. However, research on the effects of deprivation or learning can shed light on their role. For instance, the continuous administration of APV (2-amino-5-phosphonovaleric acid), an NMDA receptor antagonist, following a deafferentation of the hindlimbs in cats, prevents reorganization of the map cortices adjacent to that of the hind paw (Kano et al. 1991). Thus, comparing the timecourse of somatotopic map reorganization (Dupont et al. 2001), afferent activity (Alford et al. 1987; De-Doncker et al. 2005) and synaptic proteins time-course reveals that these parameters follow different time-courses, and that map reorganization is limited in time and magnitude. In the end, the maps could only be the submerged part of the iceberg, and give an account of much more drastic phenomena at the synaptic level, which would not necessarily translate at the functional level. 


\section{References}

Alford EK, Roy RR, Hodgson JA, Edgerton VR (1987) Electromyography of rat soleus, medical gastrocnemius, and tibialis anterior during hind limb suspension. Exp Neurol 96:635-649

Bacaj T, Wu D, Burre J, Malenka RC, Liu X, Sudhof TC (2015) Synaptotagmin-1 and -7 Are Redundantly Essential for Maintaining the Capacity of the Readily-Releasable Pool of Synaptic Vesicles. PLoS biology 13:e1002267

Benali A, Weiler E, Benali Y, Dinse HR, Eysel UT (2008) Excitation and inhibition jointly regulate cortical reorganization in adult rats. J Neurosci 28:12284-12293

Bliss TV, Lomo T (1973) Long-lasting potentiation of synaptic transmission in the dentate area of the anaesthetized rabbit following stimulation of the perforant path. J Physiol 232:331-356

Bogen IL, Boulland JL, Mariussen E, Wright MS, Fonnum F, Kao HT, Walaas SI (2006) Absence of synapsin I and II is accompanied by decreases in vesicular transport of specific neurotransmitters. J Neurochem 96:1458-1466

Böhme MA et al. (2019) Rapid active zone remodeling consolidates presynaptic potentiation. Nat Commun 10:1085

Buonomano DV, Merzenich MM (1998) Cortical plasticity: from synapses to maps. Annual Review of Neuroscience 21:149-186

Canu MH, Picquet F, Bastide B, Falempin M (2010) Activity-dependent changes in the electrophysiological properties of regular spiking neurons in the sensorimotor cortex of the rat in vitro. Behav Brain Res 209:289-294

Canu MH, Treffort N, Picquet F, Dubreucq G, Guerardel Y, Falempin M (2006) Concentration of amino acid neurotransmitters in the somatosensory cortex of the rat after surgical or functional deafferentation. Exp Brain Res 173:623-628

Chung HJ, Xia J, Scannevin RH, Zhang X, Huganir RL (2000) Phosphorylation of the AMPA receptor subunit GluR2 differentially regulates its interaction with PDZ domain-containing proteins. J Neurosci 20:7258-7267

Coq JO, Xerri C (1998) Environmental enrichment alters organizational features of the forepaw representation in the primary somatosensory cortex of adult rats. Exp Brain Res 121:191-204

Cousins SL, Papadakis M, Rutter AR, Stephenson FA (2008) Differential interaction of NMDA receptor subtypes with the post-synaptic density-95 family of membrane associated guanylate kinase proteins. J Neurochem 104:903-913

Cull-Candy SG, Leszkiewicz DN (2004) Role of distinct NMDA receptor subtypes at central synapses. Sci STKE 2004:re16

Cunningham KL, Littleton JT (2019) Synaptic Plasticity: Close Encounters of the Tonic and Phasic Kind. Curr Biol 29:R1196-r1198

De-Doncker L, Kasri M, Picquet F, Falempin M (2005) Physiologically adaptive changes of the L5 afferent neurogram and of the rat soleus EMG activity during 14 days of hindlimb unloading and recovery. J Exp Biol 208:4585-4592

Diering GH, Huganir RL (2018) The AMPA Receptor Code of Synaptic Plasticity. Neuron 100:314-329

Dudek SM, Bear MF (1992) Homosynaptic long-term depression in area CA1 of hippocampus and effects of N-methyl-D-aspartate receptor blockade. Proc. Natl. Acad. Sci. USA 89:4363-4367

Dupont E, Canu M, Langlet C, Falempin M (2001) Time course of recovery of the somatosensory map following hindpaw sensory deprivation in the rat. Neurosci Lett 309:121-124

Dupont E, Canu MH, Falempin M (2003) A 14-day period of hindpaw sensory deprivation enhances the responsiveness of rat cortical neurons. Neuroscience 121:433-439

Ehlers MD (2000) Reinsertion or Degradation of AMPA Receptors Determined by Activity-Dependent Endocytic Sorting. Neuron 28:511-525

Ehlers MD, Fung ET, O'Brien RJ, Huganir RL (1998) Splice variant-specific interaction of the NMDA receptor subunit NR1 with neuronal intermediate filaments. J neurosci 18:720-730

Ehrlich I, Klein M, Rumpel S, Malinow R (2007) PSD-95 is required for activity-driven synapse stabilization. Proc. Natl. Acad. Sci. USA 104:4176-4181 
Ehrlich I, Malinow R (2004) Postsynaptic density 95 controls AMPA receptor incorporation during long-term potentiation and experience-driven synaptic plasticity. J neurosci 24:916-927

Feldman DE, Brecht M (2005) Map plasticity in somatosensory cortex. Science 310:810-815

Feldman DE, Nicoll RA, Malenka RC (1999) Synaptic plasticity at thalamocortical synapses in developing rat somatosensory cortex: LTP, LTD, and silent synapses. J Neurobiol 41:92-101

Fourneau J, Canu MH, Cieniewski-Bernard C, Bastide B, Dupont E (2018) Synaptic protein changes after a chronic period of sensorimotor perturbation in adult rats: a potential role of phosphorylation/O-GIcNAcylation interplay. J Neurochem 147:240-255

Fourneau J, Cieniewski-Bernard C, Canu M-H, Duban-Deweer S, Hachani J, Bastide B, Dupont E (2020) Optimization of 2-DE and multiplexed detection of O-GICNAcome, phosphoproteome and whole proteome protocol of synapse-associated proteins within the rat sensorimotor cortex. J Neurosci Methods 343:108807

Fu M, Zuo Y (2011) Experience-dependent structural plasticity in the cortex. Trends Neurosci 34:177187

Futai K, Kim MJ, Hashikawa T, Scheiffele P, Sheng M, Hayashi Y (2007) Retrograde modulation of presynaptic release probability through signaling mediated by PSD-95-neuroligin. Nature neuroscience 10:186-195

Groc L, Heine M, Cognet L, Brickley K, Stephenson FA, Lounis B, Choquet D (2004) Differential activity-dependent regulation of the lateral mobilities of AMPA and NMDA receptors. Nature neuroscience 7:695-696

Gu Q (2002) Neuromodulatory transmitter systems in the cortex and their role in cortical plasticity. Neuroscience 111:815-835

Hayashi T, Huganir RL (2004) Tyrosine phosphorylation and regulation of the AMPA receptor by SRC family tyrosine kinases. J neurosci 24:6152-6160

Holtmaat A, Svoboda K (2009) Experience-dependent structural synaptic plasticity in the mammalian brain. Nature reviews Neuroscience 10:647-658

Kano M, lino K, Kano M (1991) Functional reorganization of adult cat somatosensory cortex is dependent on NMDA receptors. Neuroreport 2:77-80

Kole K, Scheenen W, Tiesinga P, Celikel T (2018) Cellular diversity of the somatosensory cortical map plasticity. Neurosci biobehavl rev 84:100-115

Kwon SE, Chapman ER (2011) Synaptophysin regulates the kinetics of synaptic vesicle endocytosis in central neurons. Neuron 70:847-854

Langlet C, Canu MH, Falempin M (1999) Short-term reorganization of the rat somatosensory cortex following hypodynamia-hypokinesia. Neurosci Lett 266:145-148

Li J, Park E, Zhong LR, Chen L (2019) Homeostatic synaptic plasticity as a metaplasticity mechanism - a molecular and cellular perspective. Curr Opin Neurobiol 54:44-53

MacDermott AB, Mayer ML, Westbrook GL, Smith SJ, Barker JL (1986) NMDA-receptor activation increases cytoplasmic calcium concentration in cultured spinal cord neurones. Nature 321:519-522

Morey-Holton ER, Globus RK (2002) Hindlimb unloading rodent model: technical aspects. J Applied Physiol 92:1367-1377

Mysoet J, Canu MH, Cieniewski-Bernard C, Bastide B, Dupont E (2014) Hypoactivity affects IGF-1 level and PI3K/AKT signaling pathway in cerebral structures implied in motor control. PloS one 9:e107631

Mysoet J, Dupont E, Bastide B, Canu MH (2015) Role of IGF-1 in cortical plasticity and functional deficit induced by sensorimotor restriction. Behavioural brain research 290:117-123

Mysore S, Tai C-Y, Schuman E (2007) Effects of N-cadherin disruption on spine morphological dynamics. Front Cell Neurosci 1

Nikitczuk JS, Patil SB, Matikainen-Ankney BA, Scarpa J, Shapiro ML, Benson DL, Huntley GW (2014) Ncadherin regulates molecular organization of excitatory and inhibitory synaptic circuits in adult hippocampus in vivo. Hippocampus 24:943-962 
Nithianantharajah J, Levis H, Murphy M (2004) Environmental enrichment results in cortical and 81:200-210

Pearson JC, Finkel LH, Edelman GM (1987) Plasticity in the organization of adult cerebral cortical maps: a computer simulation based on neuronal group selection. J neurosci 7:4209-4223

Raja MK, Preobraschenski J, Del Olmo-Cabrera S, Martinez-Turrillas R, Jahn R, Perez-Otano I, Wesseling JF (2019) Elevated synaptic vesicle release probability in synaptophysin/gyrin family quadruple knockouts. Elife 8

Reid B, Martinov VN, Njå A, Lømo T, Bewick GS (2003) Activity-dependent plasticity of transmitter release from nerve terminals in rat fast and slow muscles. J neurosci 23:9340-9348

Schnell E, Sizemore M, Karimzadegan S, Chen L, Bredt DS, Nicoll RA (2002) Direct interactions between PSD-95 and stargazin control synaptic AMPA receptor number. Proc. Natl. Acad. Sci. USA 99:13902-13907

Scott DB, Blanpied TA, Swanson GT, Zhang C, Ehlers MD (2001) An NMDA receptor ER retention signal regulated by phosphorylation and alternative splicing. J neurosci 21:3063-3072

Seidenman KJ, Steinberg JP, Huganir R, Malinow R (2003) Glutamate receptor subunit 2 Serine 880 phosphorylation modulates synaptic transmission and mediates plasticity in CA1 pyramidal cells. J neurosci 23:9220-9228

Shiotani H, Maruo T, Sakakibara S, Miyata M, Mandai K, Mochizuki H, Takai Y (2017) Agingdependent expression of synapse-related proteins in the mouse brain. Genes to Cells 22:472484

Stan A et al. (2010) Essential cooperation of N-cadherin and neuroligin-1 in the transsynaptic control of vesicle accumulation. Proc. Natl. Acad. Sci. USA 107:11116-11121

Steinberg JP et al. (2006) Targeted in vivo mutations of the AMPA receptor subunit GluR2 and its interacting protein PICK1 eliminate cerebellar long-term depression. Neuron 49:845-860

Trinel D, Picquet F, Bastide B, Canu MH (2013) Dendritic spine remodeling induced by hindlimb unloading in adult rat sensorimotor cortex. Behav brain res 249:1-7

Vickers CA, Stephens B, Bowen J, Arbuthnott GW, Grant SG, Ingham CA (2006) Neurone specific regulation of dendritic spines in vivo by post synaptic density 95 protein (PSD-95). Brain Res 1090:89-98

Wallace H, Fox K (1999) Local cortical interactions determine the form of cortical plasticity. J Neurobiol 41:58-63

Wang X et al. (2013) Kalirin-7 mediates cocaine-induced AMPA receptor and spine plasticity, enabling incentive sensitization. J neurosci 33:11012-11022

Xerri C (2008) Imprinting of idiosyncratic experience in cortical sensory maps: neural substrates of representational remodeling and correlative perceptual changes. Behav Brain Res 192:26-41

Yong AJH, Tan HL, Zhu Q, Bygrave AM, Johnson RC, Huganir RL (2020) Tyrosine phosphorylation of the AMPA receptor subunit GluA2 gates homeostatic synaptic plasticity. Proc. Natl. Acad. Sci. USA 117:4948-4958

Yuan A, Rao MV, Veeranna, Nixon RA (2017) Neurofilaments and Neurofilament Proteins in Health and Disease. Cold Spring Harb Perspect Biol 9

Yuan A et al. (2018) Neurofilament light interaction with GluN1 modulates neurotransmission and schizophrenia-associated behaviors. Transl Psychiatry 8:167 
(A) P-Synapsin 1 (ser62/67)

\begin{tabular}{|c|c|c|c|c|c|}
\hline DO & D1 & D7 & D14 & $R 6$ & R24 \\
\hline $\sin$ & bata & $=13$ & 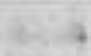 & 5: & Eica \\
\hline
\end{tabular}

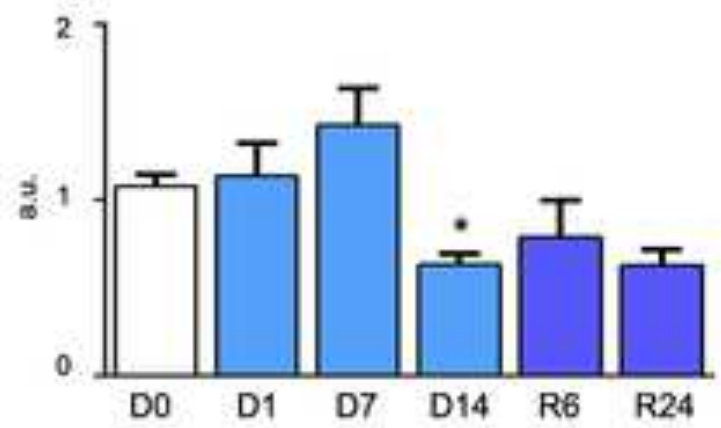

(C) Synaptophysine
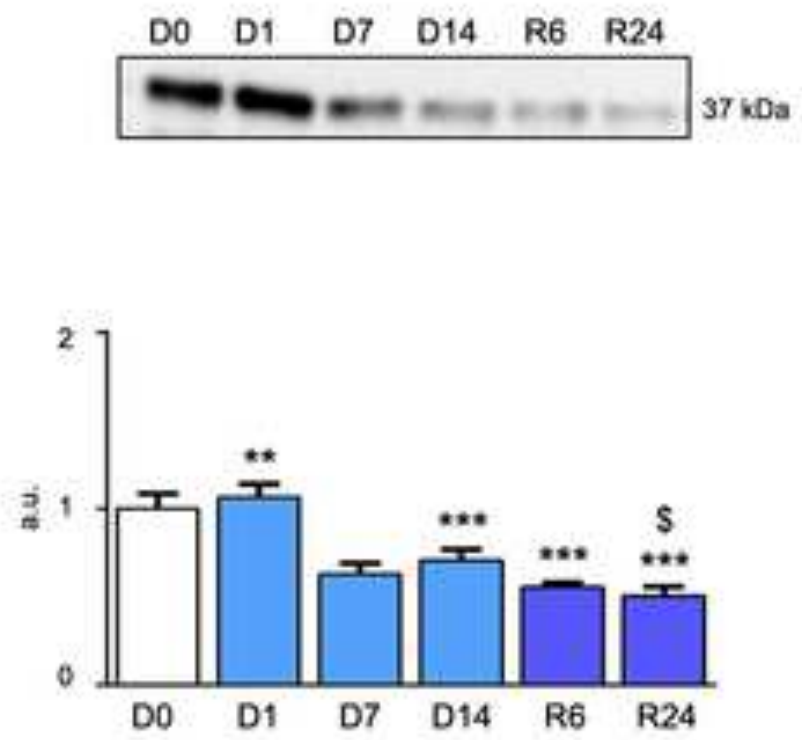

(B) Synapsin 1
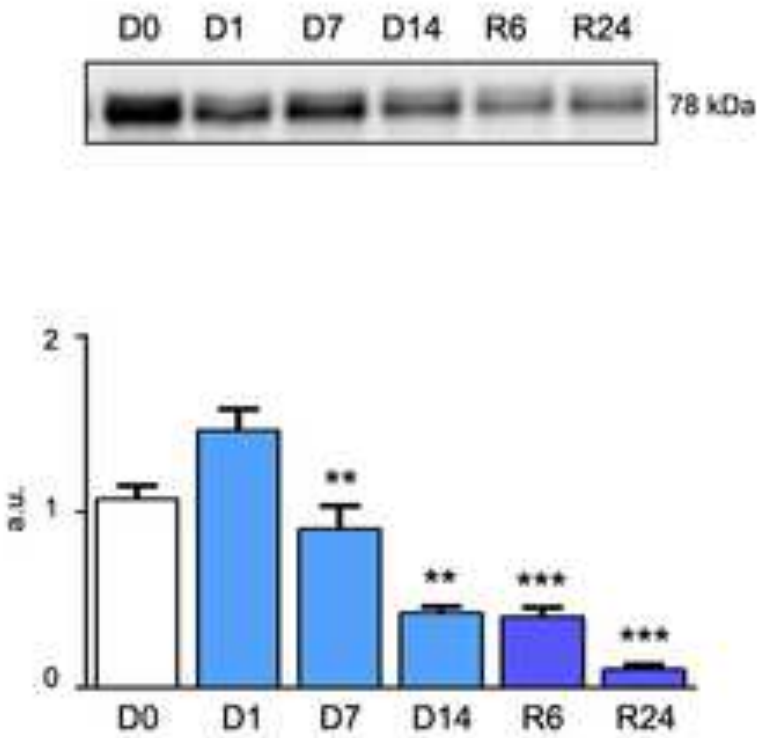

(D) Synaptotagmine 1
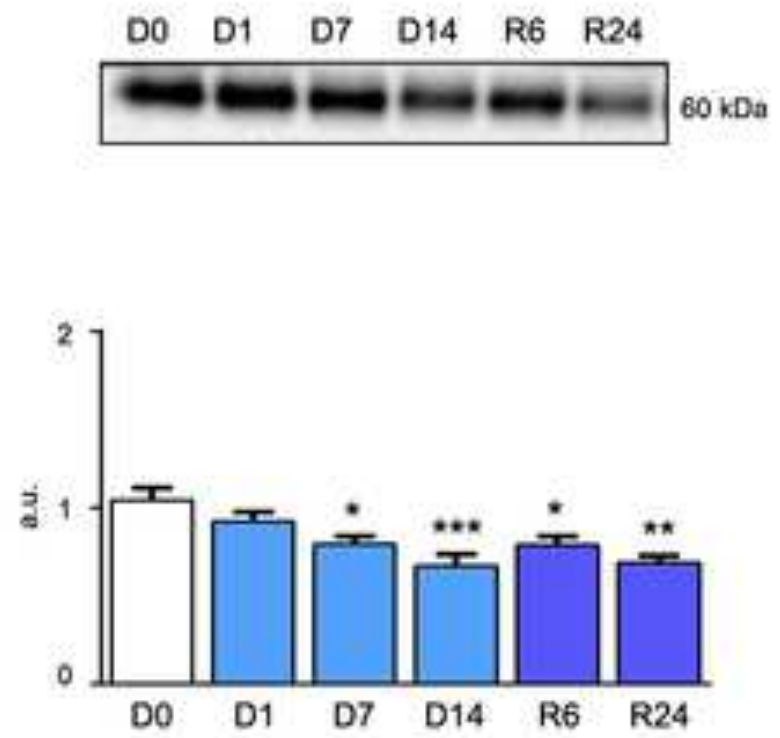
$\begin{array}{ll}\text { Figure } 2 \text { revised } & \begin{array}{l}\text { Click here to access/download;Figure;Fourneau et al - Figure } 2-\underline{\underline{ \pm}} \\ \text { revised.tif }\end{array}\end{array}$

$\begin{array}{ll}\text { Figure } 2 \text { revised } & \begin{array}{l}\text { Click here to access/download;Figure;Fourneau et al - Figure } 2-\underline{\underline{ \pm}} \\ \text { revised.tif }\end{array}\end{array}$

(A) P-AMPAR GluA2 (3-tyr)

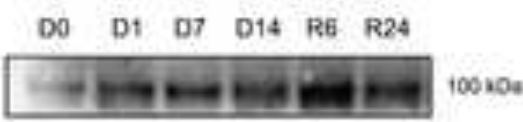

(B) P-AMPAR GIUA2 (ser880)

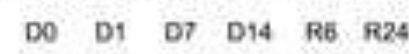

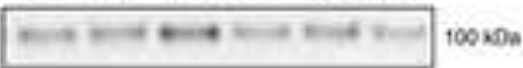
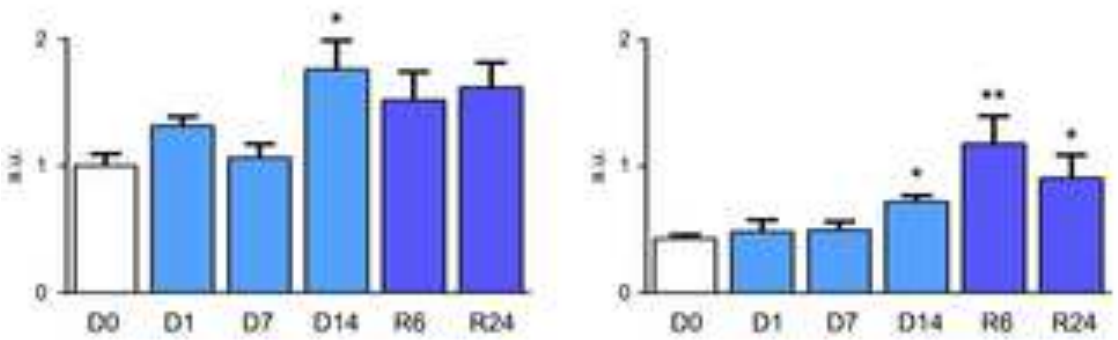

(D) P-AMPAR GluA1 (ser845)

(E) AMPAR GIUA1
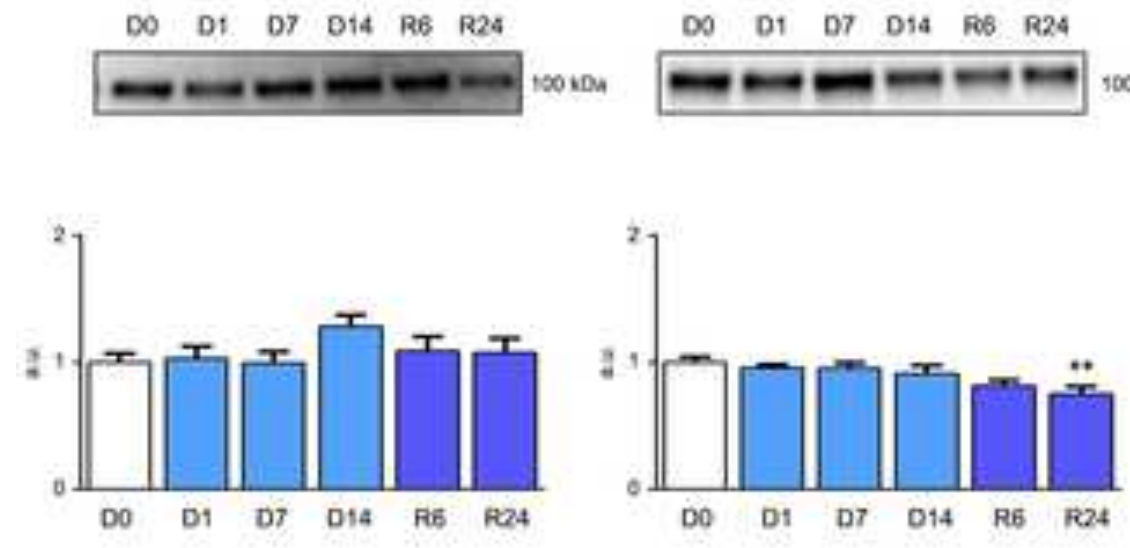

(F) P-NMDAR GluN1 (ser897) (G) NMDAR GluN1
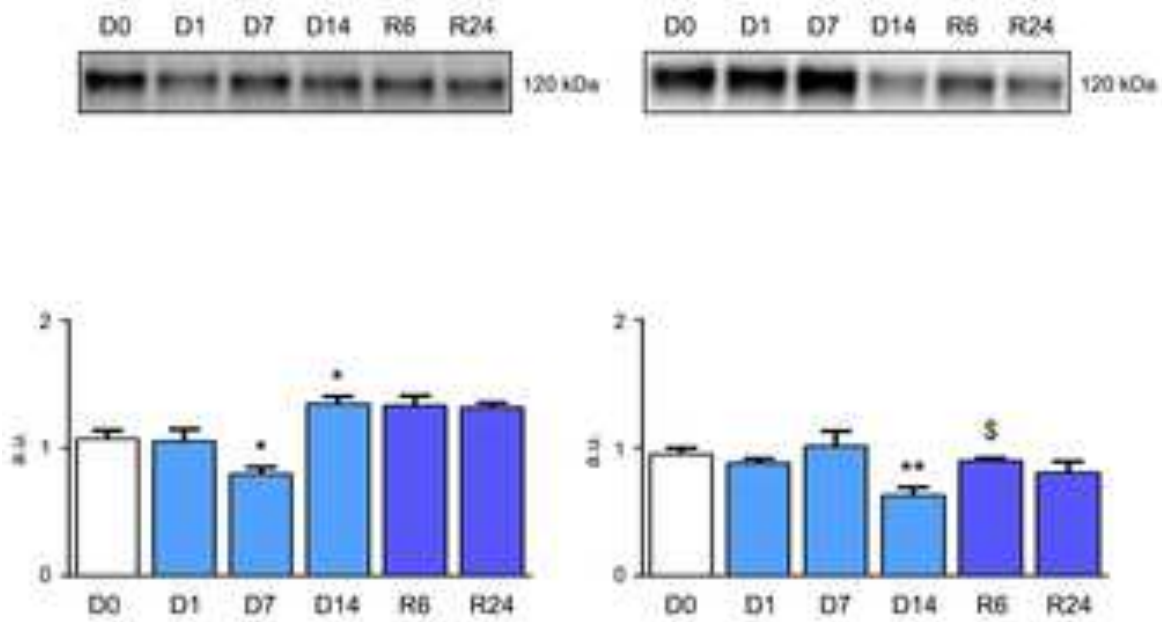

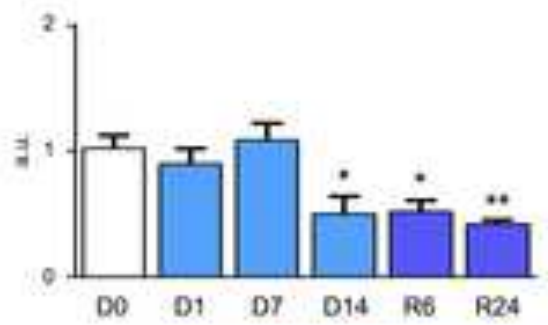

(C) AMPAR GluA2

De D1 D7 D14 R6 RQ4

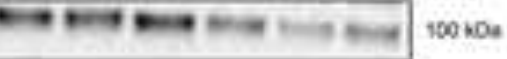

$160+0 a$

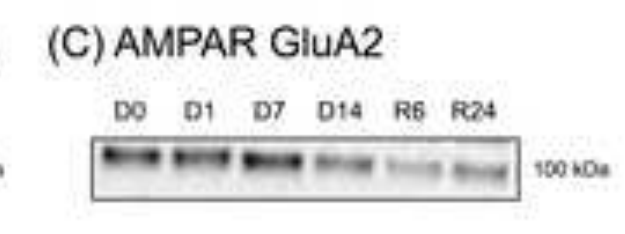

2060

$120 \times 04$

ar




\section{(A) PSD-95}
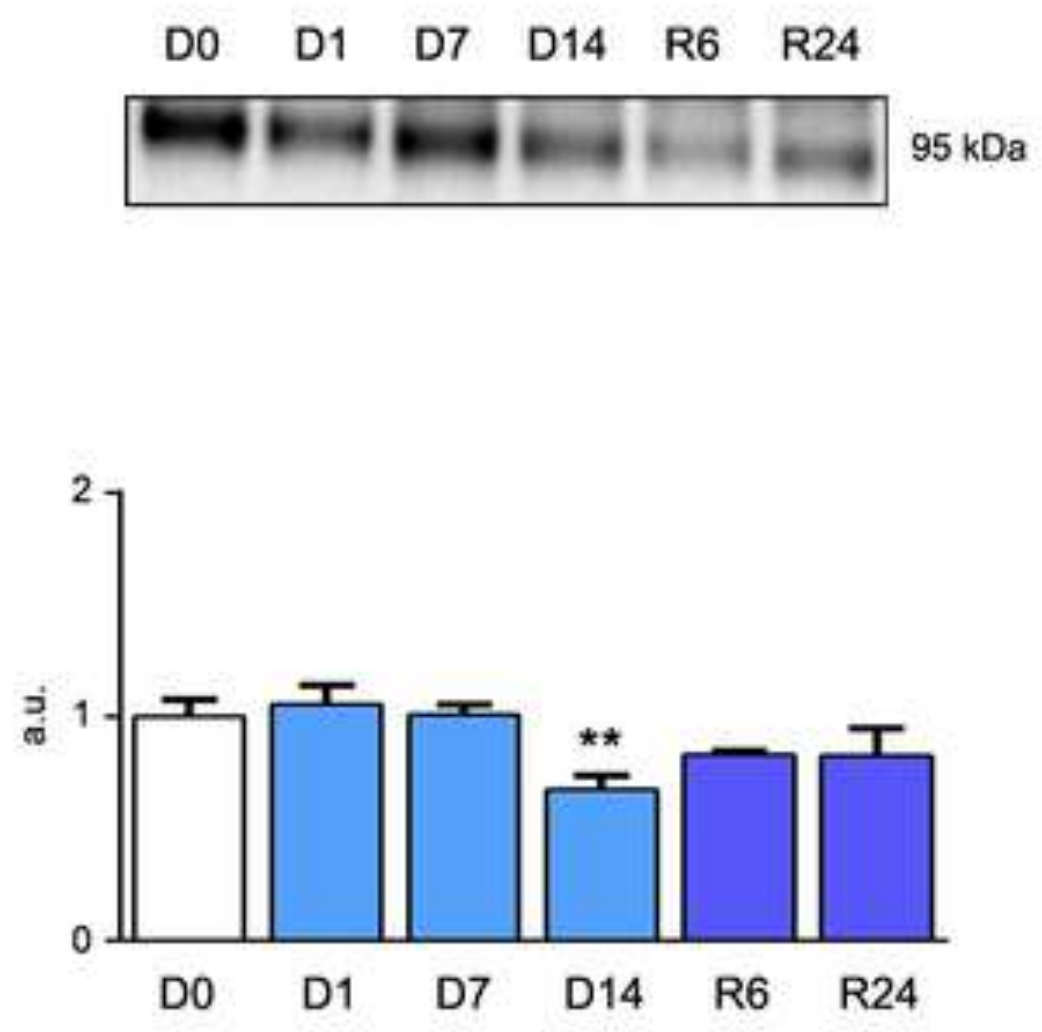

(B) N-cadherin
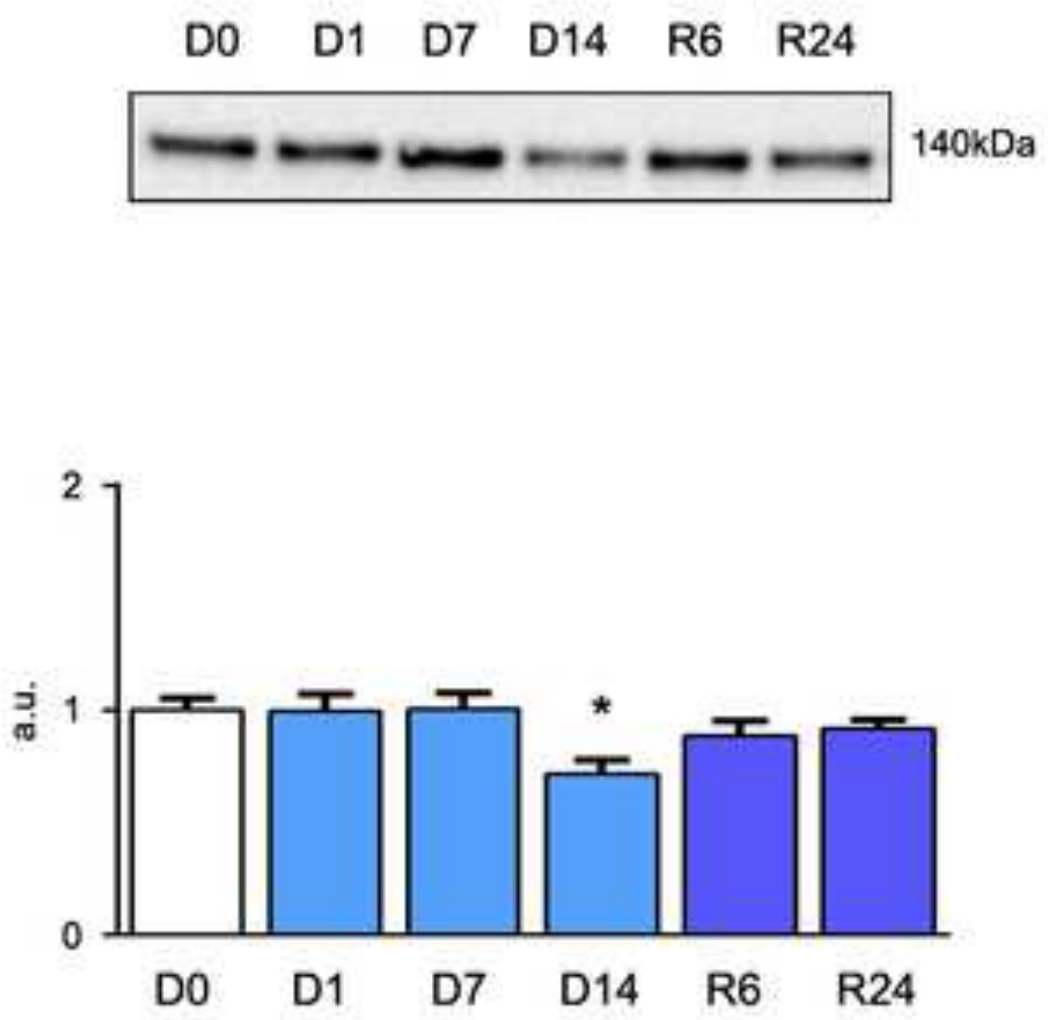
(A) Neurofilament-L
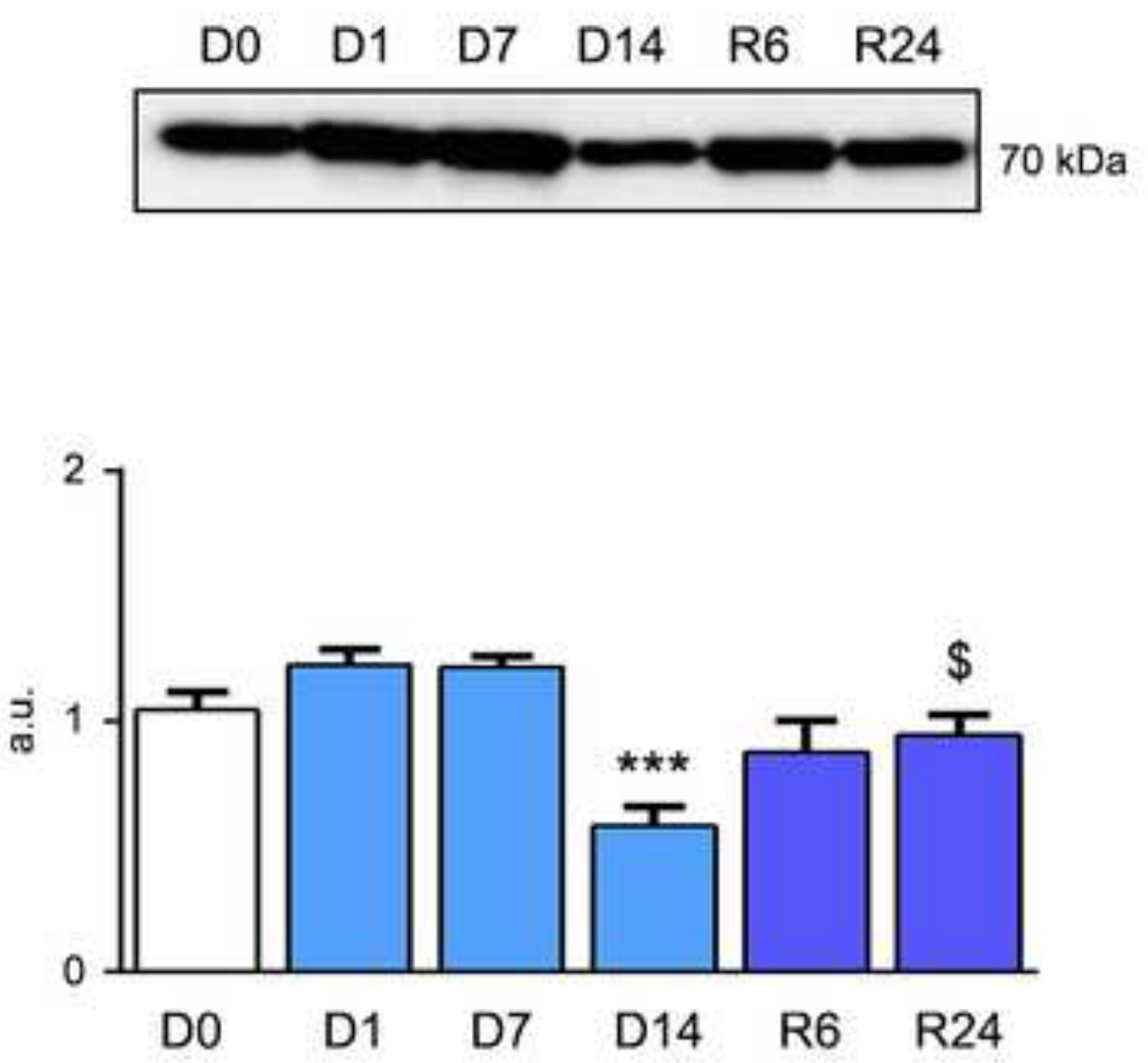

(B) Neurofilament-M
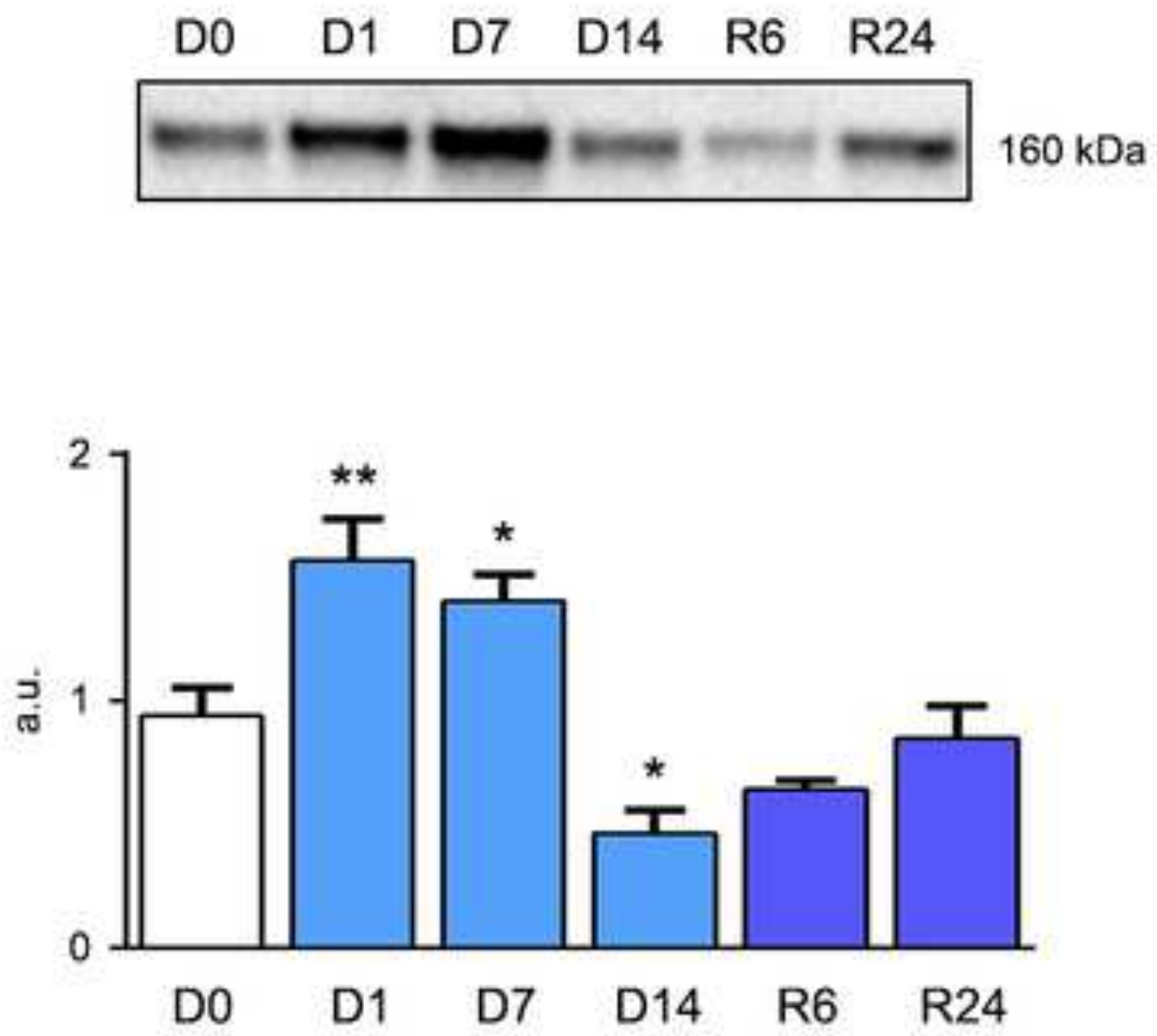
Table 1: List of primary antibodies

\begin{tabular}{|c|c|c|}
\hline Primary antibody & Reference & Dilution \\
\hline \multicolumn{3}{|c|}{ Pre-synaptic proteins } \\
\hline Phospho-synapsin 1 (ser62/67) & Merck Millipore Ab9848 & 1:1000 \\
\hline Synapsin 1 & Merck Millipore Ab1543 & $1: 20000$ \\
\hline Synaptophysine & Cell Signaling Technology \#4329 & $1: 2000$ \\
\hline Synaptotagmine 1 (D33B7) & Cell Signaling Technology \#14558 & $1: 2000$ \\
\hline \multicolumn{3}{|c|}{ Post-synaptic proteins } \\
\hline Phospho-AMPA Receptor (GluA2) (ser880) & Merck Millipore MABN103 & 1:1000 \\
\hline $\begin{array}{l}\text { Phospho-AMPA Receptor (GluA2) } \\
\text { (tyr869/tyr873/tyr876) }\end{array}$ & Cell Signaling Technology \#3921 & 1:1000 \\
\hline AMPA Receptor (GluA2) (D39F2) & Cell Signaling Technology \#5306 & $1: 2000$ \\
\hline Phospho-AMPA Receptor (GluA1) (ser845) & Cell Signaling Technology \#8084 & $1: 1000$ \\
\hline AMPA Receptor (GluA1) (D4N9V) & Cell Signaling Technology \#13185 & $1: 2000$ \\
\hline Phospho-NMDA Receptor 1 (GluN1) (ser897) & Cell Signaling Technology \#3385 & 1:1000 \\
\hline NMDA Receptor (GluN1) (D65B7) & Cell Signaling Technology \#5704 & $1: 2000$ \\
\hline \multicolumn{3}{|c|}{ Scaffolding protein } \\
\hline PSD-95 & Cell Signaling Technology \#2507 & $1: 2500$ \\
\hline \multicolumn{3}{|c|}{ Trans-synaptic adhesion protein } \\
\hline $\mathrm{N}$-cadherin & Cell Signaling Technology \#4061 & 1:1000 \\
\hline \multicolumn{3}{|c|}{ Cytoskeleton proteins } \\
\hline Neurofilament-L (C28E10) & Cell Signaling Technology \#2837 & $1: 2000$ \\
\hline Neurofilament-M (RMO 14.9) & Cell Signaling Technology \#2838 & $1: 2000$ \\
\hline
\end{tabular}


Table 2: Summary table. Changes in expression and activation of the different classes of synaptic proteins during a sensorimotor perturbation (D0, D1, D7, D14) and during a recovery phase (R6 and R24). Red: decrease; green: increase.

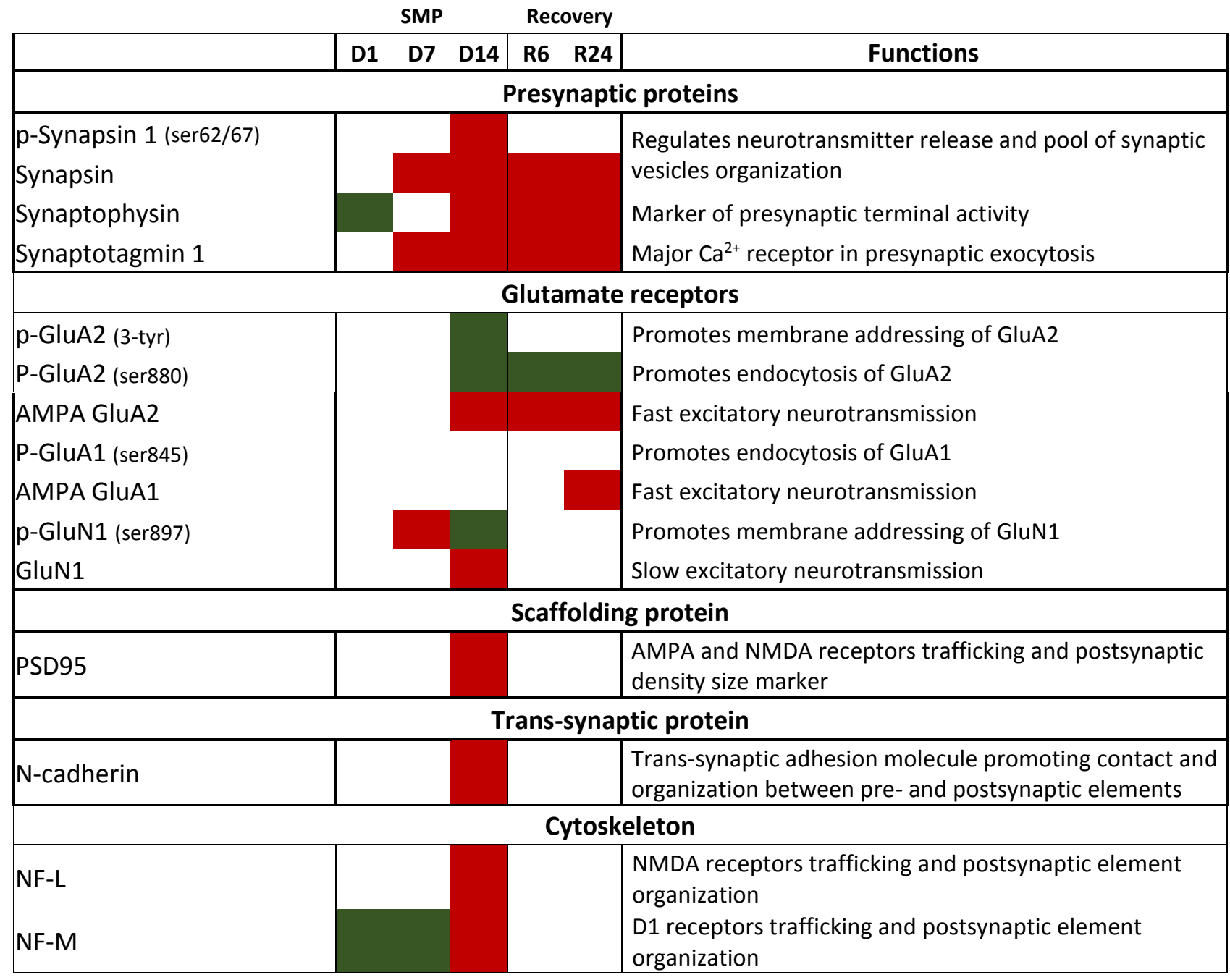

